by syncope, and a heart uncontracted after death. I regret that I have no sphygmographic evidence bearing upon this, but the failure of pulse and heart are sufficiently apparent. It would seem that a certain force is required for the accom. plishment of the transudation which constitutes renal dropsy, failing which this does not occur, however other circumstances may invite it. Yomiting and diarrhoea may take its place.

The dropsy of kidney disease is evidently connected with the retention of renal excreta, which exert some special action upon the capillaries which at once increases transudation and hinders the circulation. This is not inflammation, but may remotely resemble it, or we may regard it as akin to secretion and as tending to relieve the blood of its morbid elements. The attendant hindrance I have dwelt upon in the first lecture, together with its effect upon the arterial system. The association of dropsy with this difficulty points significantly to its position in the capillaries rather than the arterioles. It is improbable that the transudation, which is necessarily of capillary origin, would be thus promptly poured out were there any considerable constriction of the arterioles to cut off the blood from the ultimate ressels. Among the circumstances which conduce to early renal dropsy is the state of the respiratory organs, which is commonly found with this condition. In a large proportion of cases there is broncho-pneumonia or some allied con dition, which must assist the process by hindering the return of venous blood.

'I'hree stages are to be recognised in the natural course of renal dropsy : its accession, its removal, and its reappearance. This division, of course, applies only to cases which become chronic and go on to the latest issues of the disease. Numbers happily get well shortly after the outset; for such there are no subsequent stages; others are debarred from them by early death. Taking the instances where the kidneys are irrecoverable and yet allow of a protracted existence, what happens is this: the heart and arteries slowly become hypertrophied, the arterial tension increases, the pulse hardens, the urine becomes superabundant, and the dropsy lessens and then disappears. With the access of the disease we have the tension increased to a certain degree and with this dropsy; with a further increase of tension and concomitant changes in the heart and arteries the dropsy goes. This result of the vis medicatrix nature is often placed to the credit of the last drug or the last medical attendant. How is it brought about? Probably in two ways; the increased blood-pressure is a diuretic of no mean efficacy, and the increased expansile power of the hypertrophied left ventricle draws upon the veins and pumps out the waterlogged ressel. But this is not the finish. The last scene of all that ends this strange eventful history is heart-failure and a return of dropsy which is now more cardiac than renal. The beneficial part of the process can be conducted only so long as the mitral valve remains efficient. A time comes, if the patient lives long enough, when the heart stretches under the strain and the mitral orifice becomes too wide to be closed by the mitral flaps. Then comes regurgitation, a mitral murmur, a return of dropsy, which often invades the thoracic cavities, often pulmonary apoplexy, and all the circumstances of mitral disease. Pulmonary apoplexy and hrmoptysis may ensue simply from renal disease without any affection of the heart excepting what renal disease entails. I have given examples of this in the paper that I have more than once referred to.

The treatment of renal dropsy is by no means unsatis factory, since we often have with us a strong-siding champion-Time. We must not be guided solely by a prior reasoning or theoretical considerations, but largely by experience. We have to trim and adjust and pursue a system of compromise. We have anxmia on one hand and uræmia on the other, and must steer between Scylla and Charybdis. We have to depurate, to dehydrate, but not to anæmiate. We must evacuate, but not exhaust. "Spare diet and spring water clear" may purify the blood, but are not remedies for anæmia. Watery purgatives, compound jalap powder, sulphate of magnesia, and under extreme circumstances elaterium, may be given periodically and alternately with hot-air baths. Sudorifics in the shape of drugs are useless as remedies for dropsy, but I have known this, when obstinate and extensive, to be entirely removed under the influence of hot air, which I have been in the habit of applying only below the knees; the effect is general and sufficient without being excessive. Of the medicines of the diuretic class the only one of special use is digitalis, and this is so valuable that $I$ have laid down a rule for myself from which I seldom depart-if there be dropsy in the course of renal disease give digitalis. This is not merely a diuretic, but probably has an action on the cardiovascular system which is beneficial under the circumstances. A very low diet does not do ; I give fish. generally, and have often exchanged it for a little meat with obvious advantage. The treatment of renal disease is. often overdone in the way of taking too much out of the patient and not putting enough in. For the more chronic cases iron is generally beneficial; the perchloride may be conveniently associated with digitalis, and enough sulphate of soda or of magnesia to obviate any constipating effect. I may add a word about tapping which is much what I have said in reference to cardiac dropsy. Tap the pleuræ or the peritoneum with confidence, but leare the legs alone. Relieving the abdomen is often the best way of relieving the lower extremities, for it takes the pressure off the vena cava. With regard to the pleuræ, by remoring fluid from them we achieve two ends : not only do we ease the breathing, but by taking pressure off the pulmonary vessels we facilitate the return of venous blood, and thus promote the absorption of dropsy fluid in every part of the bodv.

Allied to the dropsy of renal disease is that of chlorosis both are essentially dependent on the failure of a natural excretion and its retention in the blood. I have no time to dwell upon this, but may briefly say that one way in which the toxic agent acts, as does that of kidney disease, is by increasing the arterial tension. It took me by surprise when I found by applying the sphygmograph in this variety of dropsy that with these pallid and feeble creatures given to fainting, as full of murmurs as an Eolian harp-" most musical, most melancholy"- - the force of the pulse was increased instead of diminished. It has long been known that these subjects of green sickness were the better for being purged, and for some time suspected that a toxic retention was concerned in the production of the symptoms. In general estimation this toxic element is of uterine origin, and I daresay it may largely be so, but I have often heard Sir Andrew Clark maintain that it was alvine, and thus explain the benefit derived from cathartics. My object is chiefly to show that together with œdema in chlorosis we have increased arterial tension where we should least expect it, and recognise a similar attitude of dropsy and vessel to that which pertains to renal disease. All this helps to explain what we have already learned from experience, that whatever else we do in chlorotic anæmia our endeavours must be to rid the blood of its morbid superfluities, and stimulate the eliminative function of the uterus. 'Ihus we find other warrant than that of experience for conjoining aloes with the necessary iron, and only find in new inquiry fresh reasons for the time. honoured practice.

\section{A MODIFICATION OF THE OPERATION OF ENTEROPLASTY FOR SIMPLE STRICTURE OF THE INTESTINE.}

BY A. W. MAYO ROBSON, F.R.C.S. ENG.,

SEYIOR SURGEON TO THE GENERAL INTIRMARY, LELDS; PROYESSOR OF THE ROYAL COLLEGE OF SURGEONS OP WNGLAND.

THE method of overcoming stricture of the pylorus by longitudinal section and transverse suture of the incision, originally performed by Heineke and afterwards followed up by Mikulicz, was first applied to a case of simple stricture of the intestine by Mr. H. Allingham. ${ }^{3}$ The modification of the operation by the use of the bone bobbin will, I think, be found to present the following advantages: (1) rapidity of execution, since only two continuous sutures are requiredone to unite the mucous margin, the other the serous; (2) an inmediately patent and efficient channel, prerenting tension above the newly joined gut; and (3) protection to the line of sutures until the lymph has become partly organised. The following case is of interest, not only from 
the operative point of view, but from the history of ante cedent ulceration of bowel with perforation and recovery.

A thin, delicate girl aged sixteen was sent to me by her medical man, Dr. J. Russell of Batley, on account of a fæcal fistula in the right crecal region, through which pus and liquid faces had been passing for some months, during which time she had been gradually losing weight and strength. She gave the history of having had an illness eighteen months previously, when a swelling with tenderness developed in the right side of the abdomen. She had diarrhoa and was feverish, and was told that there was inflammation of the bowels. After some weeks an abscess developed over the cxcum and was opened, a quantity of foul pus being let out. A week after the abscess had been opened fæcal matter began to be discharged from the wound, and this had continued since, though the bowels had been occasionally moved through the anus. On admission to hospital the patient was extremely thin, her bones showing visibly under the skin. There was a frecal fistula midway between the umbilicus and the right anterior superior spine of the ilium, and the skin around the opening was excoriated, red, and intamed by the irritation of liquid facal discharge and pus. The abdomen was quite flat, and no tumour could be felt. Charcoal administered by the mouth appeared at the fistula in thirteen hours. On July 10th, after laying open the rather extensive sinuses leading from the fistula, scraping them freely with a Volkmann's spoon and as far as possible asepticising them by means of a 1 in 1000 perchloride solution, the abdomen was opened by an incision of three inches, the fistula being the centre of the incision. Adhesions were separated by the fingers and the affected gut brought outside the wound, the peritoneal cavity being protected by sponge packing. The fistula was in the ileum, and while the fingers would easily pass upwards nothing larger than a No. 12 catheter would pass through a stricture fully an inch in length just below the fistula. After passing a director through the stricture, which was evidently cicatricial, it was divided in the direction of the length of the bowel. A decalcified bone bobbin was then inserted and the cut edges were brought together transversely over it, as shown in the diagrams. A continuous catgut suture was

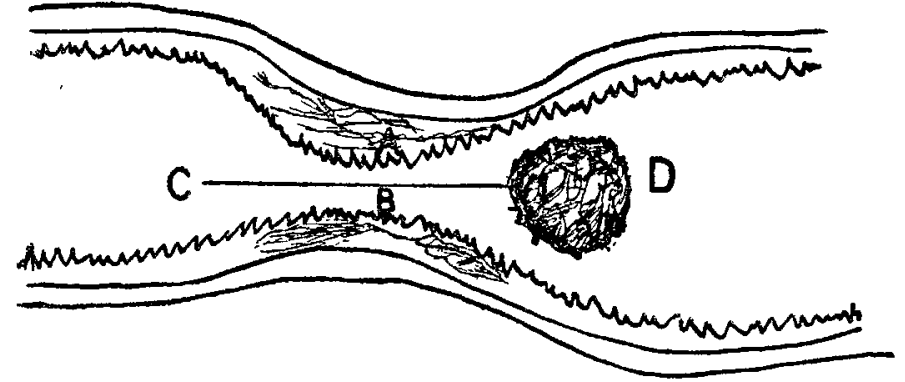

First stage, showing incision from fistula $\mathrm{o}$ through to $\mathrm{c}$

ased to unite the mucous margins, and a silk suture the serous surfaces, thus restoring the continuity of the intestinal channel. After carefully cleansing the surrounding structures, the peritoneum, aponcurosis, and skin were apposed

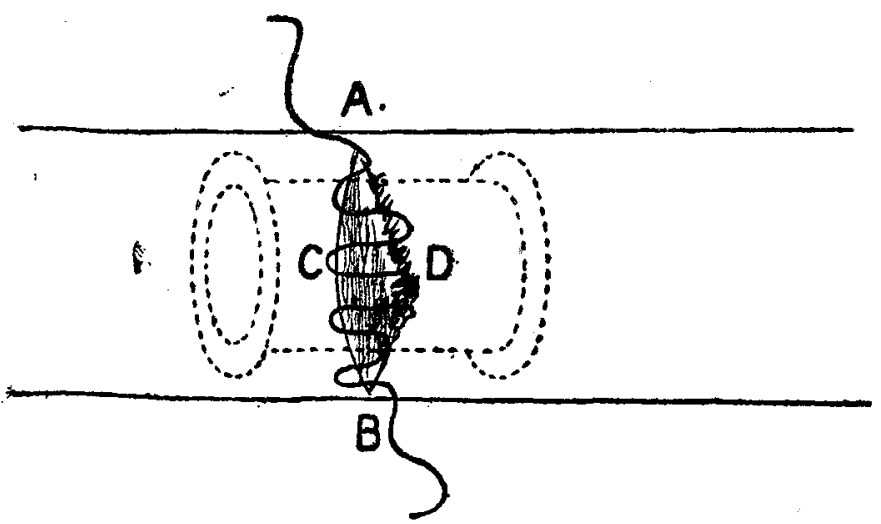

Becond stage, showing sides of incision $A$ a drawn apart and ends $\mathrm{C} D$.

in the usual manner. The patient suffered very little from shock, and the bowels were moved naturally on the second day. The deeper parts of the wound healed by first intention; the superficial by granulation. The patient's general condition began to improve at once, and she has never $\mathbf{i}_{\mathbf{i}}$ had any bowel trouble since. When seen six months later, she looked a picture of health, had gained her usual colour and flesh, and expressed herself as quite well.

Remarks.-Simple stricture of the bowel is sufficiently rare to make it worth while reporting a single instance; but this case is also of interest from an operative point of view-not simply from the success of the modification of the operation by the use of the bone bobbin, but also because it shows that a plastic peritoneal operation may be undertaken with some prospect of success, though the way into the abdomen be through a foul abscess, if, as in the present case, the walls of the abscess and the surrounding parts be purified before the abdominal cavity is opened.

Leeds.

\section{TWO CASES OF SEPTICEMIA DUE TO MIDDLE-EAR DISEASE; OPERA- TION ; RECOVERY.}

BY W. GIFFORD NASH, F.R.C.S. ENG.

CASE 1. Septic pleuro-pneumonia following a blow on the head in a boy suffering from otorrhea. - A boy aged twelve, who had had otorrhoea for five years, was boxed on the ear on June 16th, 1892. This was immediately followed by headache and seven hours later by vomiting. Next morning headache, photophobia, fever, and delirium were present. Twenty-four hours after the blow I found him lying curled up in bed, objecting to light and interference, delirious, very flushed, and with a temperature of $103^{\circ} \mathrm{F}$. and pulse 180. Half an hour later my partner, Mr. Kinsey, gave him chloroform, and 1 shaved the scalp and forcibly syringed out the right ear, removing a small granulation polypus. Three leeches were applied behind the ear and an icebag to the head. On June 18th he was still feverish, but there was no delirium. He was seen in consultation by Mr. Henry Morris, and with his sanction I trephined and gouged ont the mastoid antrum. The dura mater covering the roof of the antrum was also exposed and found to be healthy. No pus was found. On the 20th there were frontal headache and pain in the right shoulder.as also a dry hacking cough suggestive of pleurisy. On the 21st the cough and pain continued. The temperature was $103.4^{\circ}$, the pulse 120 , and the respiration 48 . On the 22nd the temperature was $104 \cdot 6^{\circ}$, the pulse 144 , and the respiration 60 . Pleuritic friction was heard over the left lower lobe and right upper and middle lobes, with numerous scattered patches of tubular breathing; there was also sweating. It was evident that septic pleuro-pneumonia was present. I proposed to explore the lateral sinus, and, if I found it thrombosed, to tie the internal jugular vein. 'The trephine was applied to the mastoid process over the lateral sinus. This did not pulsate, but looked healthy. A hypodermic syringeful of blood was drawn off, showing that the sinus was not thrombosed. When the needle was withdrawn blood spurted from the puncture. The wound was closed and nothing further done. From June 22nd until the end of July the case was desperate. There were repeated fresh patches of pneumonia with elevation of temperature to $103^{\circ}$ or $104^{\circ}$; the pulse varied up to 144, and the respiration up to 72. At one time tubular breathing and friction were heard over the whole of the right lung and lower lobe of the left. The expectoration was fetid, and there were profuse sweating and extreme emaciation. From this desperate condition he gradually recovered. The treatment consisted of milk, eggs and brandy, with quinine and digitalis. During August there were slight occasional rises of temperature. On Aug. 31st he got up, and on Oct. 1st he was allowed out of doors. He then looked as well as he did before the illness. There was no discharge from the right ear, and he could hear a watch tick at 12 in. The right side of the chest was much contracted. In August, 1894, he was in perfect health; the chest showed no sign of contraction; there was no deficiency of expansion or diminution of breath sounds, and no discharge from the ear.

Remarks.-I do not claim that the surgical measures adopted had anything to do with the recovery of this patient, but I believe it would have been culpable to have neglected them when it is considered how fatal these cases are when treated by merlical means. d [ $T$ l ere can be very little 